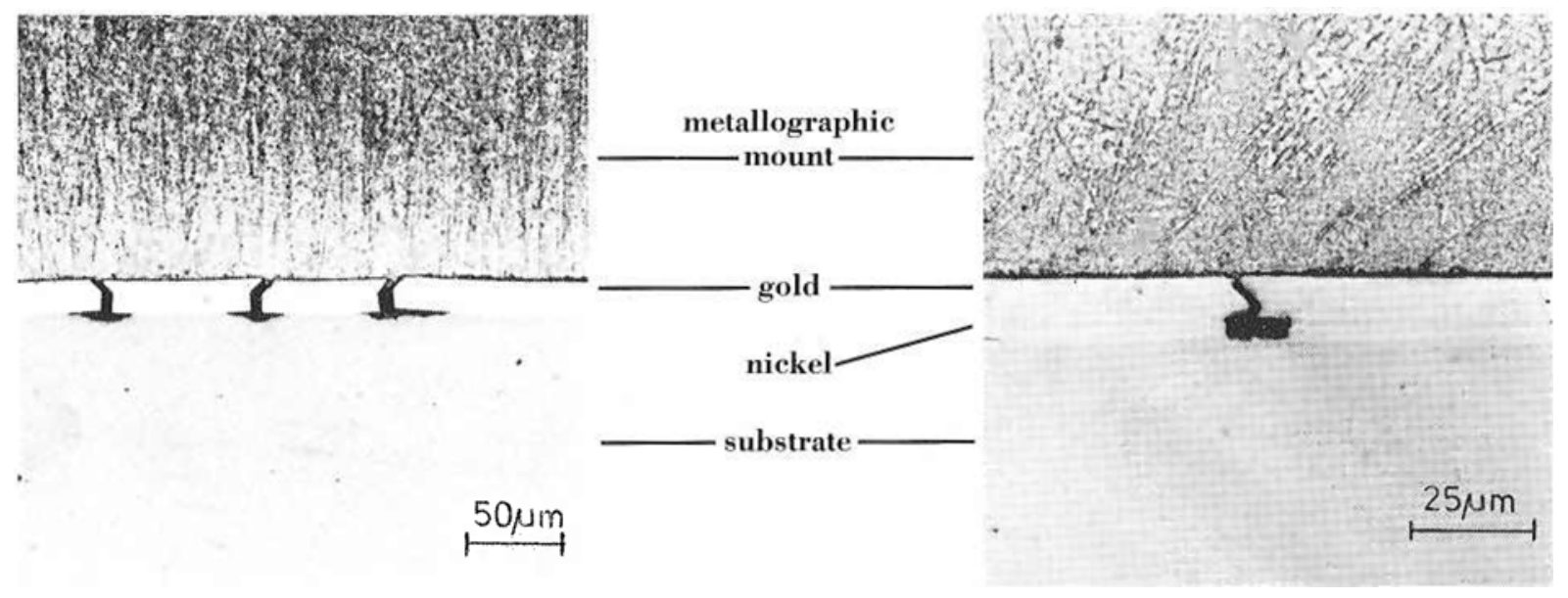

Fig. 7 Cross section through a temple, electroplated with white gold and bent prior to testing in artificial perspiration. Corrosion of the substrate is not restricted to the tip of the cracks in the coating but also spreads laterally underneath the gold layer

\section{Typical Corrosion Problems on Electroplated Frames}

The corrosion behaviour of gold plated spectacle frames is characterised by the fact that a noble metal coating is deposited onto a less noble substrate. Therefore, corrosion only occurs where the coating is defective (cracks, pores, etc.). It is aggravated by the coupling of a large cathodic area of gold with low current density to a small anodic area of base metal alloy with high corrosion current density. This is illustrated in Figure 7 where a white gold deposit, flash coated with rhodium (not visible on the microsection), was cracked by bending prior to being tested in artificial perspiration. The base metal is corroded at the bottom of the cracks with lateral spreading, eventually leading to blistering or flaking
Fig. 8 Cross section through a temple, electroplated with nickel and 18 carat gold copper-cadmium alloy, after bending and 10 days exposure to artificial perspiration. The nickel undercoat is corroded in preference to the substrate alloy

of the gold layer. It should be mentioned here that, due to their sulphur content, bright nickel deposits sometimes have a higher corrosion rate than the substrate material. In the example of Figure 8 the intermediate nickel layer has corroded through a crack in an 18 carat gold-copper-cadmium deposit after 10 days exposure to artificial perspiration whereas the substrate alloy was not attacked.

This brief insight into the manufacture of spectacle frames shows that a properly deposited gold alloy layer can protect them from corrosion and maintain their bright decorative appearance for a long time. However, as in the case of other products, only precise material specifications and careful process control during their production will ensure consistent high quality.

\title{
Bibliographies on Industrial Applications of Gold
}

The growing importance of gold and its alloys in industry has resulted in a considerable increase in the number of papers dealing with research on them or with their applications. A large portion of this literature has been accumulated by the International Gold Corporation Limited and this has facilitated the preparation of bibliographies covering the following subjects:

- Carat gold alloys and their use in the fabrication of jewellery, by W. S. Rapson

- Gold in catalysis, by F. H. Lancaster and W. S. Rapson.

Updated versions of these, as well as bibliographies covering additional fields of gold usage, are planned for the future and will be announced in Gold Bulletin as they become available.

Copies of these bibliographies (in standard microfiche form only) may be obtained by writing to the International Gold Corporation Limited, P.O. Box 61809, Marshalltown, 2107, South Africa. 